\title{
Identification of Host Plant Resistance to Anthracnose in Greater Yam (Dioscorea alata L.)
}

\author{
R.S. Arya ${ }^{1}$, M.N. Sheela ${ }^{2 *}$, M. L. Jeeva ${ }^{2}$ and P.V. Abhilash ${ }^{2}$ \\ ${ }^{1}$ College of Agriculture, Vellayani, Thiruvananthapuram 695 522, Kerala, India \\ 2 ICAR-Central Tuber Crops Research Institute, Sreekariyam, Thiruvananthapuram 695017, \\ Kerala, India
}

*Corresponding author

\section{A B S T R A C T}

\section{Keywords}

Greater yam, Dioscorea alata L., Anthracnose, Colletotrichum gloeosporioides, Screening, Resistance

Article Info

Accepted:

12 July 2019

Available Online:

10 August 2019
Anthracnose, caused by Colletotrichum gloeosporioides Penz., is one of the most serious leaf and vine epiphytotic disease of greater yam (D. alata) in India. Forty greater yam accessions were screened in the field for resistance to anthracnose disease by whole plant area scoring method. The accessions were also evaluated for resistance in the laboratory using an excised leaf technique with pure isolates of Colletotrichum gloeosporioides Penz. Significant differences in the lesion/disease scores among greater yam genotypes, ranging from 0 (immune) to 5 (susceptible), were observed under both laboratory and field conditions. Resistance evaluations under both conditions consistently classified the genotypes as resistant and susceptible lines which is useful for future breeding programmes. Highly resistant lines viz. Da 110, Jas 2 and TCR 142 were identified for further evaluation and use in resistance breeding programmes.

\section{Introduction}

Yams (Dioscorea spp) are multi-species, polyploid and vegetatively propagated tuber crops cultivated widely in the tropics and subtropics. Dioscorea alata L., commonly known as water yam is one amongst the top ten most important yam species, listed based on staple food and agricultural perspectives (Lebot, 2009). The wide adaptation and cultivation of water yam makes it one of the most important Dioscorea species used for food in tropical and subtropical regions (Tay, 2013). Greater yam tubers possess a high nutritional content with an average crude protein content of $7.4 \%$, starch content of $75 \pm 84 \%$, and vitamin $\mathrm{C}$ content ranging from 13.0 to $24.7 \mathrm{mg} / 100 \mathrm{~g}$ (Muzac-Tucker et al., 1993).

The major limitation to the sustainable production of $D$. alata is it's susceptibility to anthracnose disease and it can cause yield reduction of upto $80 \%$ (Nwankiti and Ene, 
1984). Water yam (D. alata) was thought to be more susceptible to anthracnose than other yam species (Amusa, 1997). Gloeosporium pestis Massee was first described as the pathogen causing yam anthracnose from yam in Fiji (Winch et al., 1984). It was later reported from D. alata in India (Prasad and Singh, 1960; Singh et al., 1966) and subsequently classified as Colletotrichum gloeosporioides.

Typical symptoms of the anthracnose disease include necrotic spots on shoots, young leaves, petioles, fruits and stems, leaf and stem distortion, and shot holes. It spreads in the rainy season when temperature and moisture are favourable for the development of the disease. A detailed description of the different symptoms produced by $C$. gloeosporioides and how these develop on $D$. alata was provided by Winch et al., (1984). Genetic improvement programmes were undertaken by International Institute of Tropical Agriculture (IITA, Nigeria) and ICAR-Central Tuber Crops Research Institute (ICAR-CTCRI, India) for developing high yielding varieties of $D$. alata and $D$. rotundata with pest and disease resistance to meet farmers' requirements. More than 1000 germplasm accessions of yams have been collected, conserved and elite accessions are being used for yam improvement in these institutions and other yam improvement programmes in different countries. In all these breeding programmes, the main thrust was given for the identification of host plant resistance to anthracnose disease in greater yam among prebreeding lines and landraces.

The present investigation was carried out to determine host plant resistance for anthracnose in greater yam based on different screening techniques and the results are reported herein. This knowledge will be beneficial for developing varieties with anthracnose resistance in future.

\section{Materials and Methods}

The plant materials used for the study comprised of forty accessions of D. alata conserved in the National repository of tuber crops germplasm at ICAR-CTCRI, Sreekariyam, Thiruvananthapuram. The screening was carried out during 2017-2018. The list of greater yam accessions used for the study is given in Table 1 .

\section{Field screening}

The 40 accessions were screened in the field for anthracnose resistance. Whole plant area scoring method was done in which the lesions were rated visually on a $0-5$ scale based on the percentage of lesion appeared on leaves and vines, where $0=$ no infection, $1=1-10 \%$, $2=10-25 \%, 3=25-50 \%, 4=50-75 \%$ and $5=$ $>75 \%$ infection (Table 2).

\section{Laboratory screening}

Excised leaf assay was carried out using 40 yam genotypes, collected from germplasm collections maintained in the field gene bank at ICAR-CTCRI, Thiruvananthapuram, with varying resistance levels to anthracnose. Resistance screening was performed with pure isolates of Colletotrichum gleosporioides, which were isolated from infected leaves. Leaves of similar age and size (leaves at nodes 3 to 4, counted from the top) were collected from the field. The leaves were washed with running tap water. Monoconidial cultures of Colletotrichum gloeosporioides grown on potato dextrose agar (PDA) were scraped with a sterilized inoculation loop and transferred to a vial containing $9 \mathrm{ml}$ sterile distilled water. It is then agitated using a rotary shaker to obtain a uniform, homogenized spore suspension. A drop of the suspension was observed under $10 \mathrm{X}$ objective lens of light microscope to ensure the presence of adequate count of live spores. The 
suspension was diluted with sterile water so as to get $10^{4} \mathrm{cfu} \mathrm{ml}{ }^{-1}$. Exactly $25 \mu \mathrm{l}$ of spore suspension was inoculated onto the test leaves arranged in petriplates. Sterile water was kept as control. The petioles of the leaves were kept in contact with the folded wet tissue paper arranged inside the petriplates to prevent drying. Wet tissue paper was also placed on the lid of petriplates for maintaining humidity. The plates were incubated at room temperature. Lesions formed were rated visually after 3 days of inoculation on a $0-5$ scale based on the percentage of lesion per inoculated droplet, where $0=$ no infection, $1=$ $1-10 \%, 2=10-25 \%, 3=25-50 \%, 4=50-75 \%$ and $5=>75 \%$. The reactions of the accessions were assigned as given in table 3 .

\section{Results and Discussion}

Field screening was done by whole plant area scoring method in which the lesions appeared on leaves and vines were rated visually on a 0-5 scale. TCR 142 and Da 340 were found to be immune to anthracnose since they didn't show any trace of infection (Table 3). Many other accessions viz. Da 110, Da 293, Jas 2, TCR 113, Sree Keerthi etc. could be in the resistant category as the percentage of infected area in these plants were only 1-10\% (Score 1). Maximum infection was observed in Sree Neelima, DaH 24-6-3 and also Orissa Elite, classifying them as highly susceptible accessions (Score 5). Five percent of the total samples were immune to anthracnose whereas more than $32 \%$ were highly resistant and $25 \%$ were resistant to anthracnose in the field. Only 5\% were found to be susceptible or highly susceptible in the field.

Laboratory screening was done by excised leaf assay using 40 greater yam genotypes and the lesions formed were rated visually at 3 days after inoculation on a 0-5 scale. JAS- 2 and $\mathrm{Da} 110$ were found to be immune under laboratory conditions (Score 1), whereas Da 820, TCR 282, TCR 342, TCR 43, Da 509 and DaH 24-6-3 showed extensive infection, categorizing them as highly susceptible. As in field screening, only $5 \%$ of the samples were observed as immune in laboratory screening assay. But more than $17 \%$ were given a score of 5, classifying them as highly susceptible and $15 \%$ of the accessions were moderately susceptible.

The laboratory screening evaluation methodology was supported by Onyeka et al., (2006) and ICAR-CTCRI (2016) where tissue culture derived whole plant assay was used for assessing anthracnose resistance in greater yam. Similar laboratory and field evaluation study was carried out by Poolsawat et al., (2012) to identify host plant resistance in grape wine to anthracnose.

Resistant varieties Sree Keerthi, TCR 113, DaH 58 FG and DaH 9-196 showed similar grade of infection, all with a score of 1 in both field screening and laboratory screening, ensuring the effectiveness of laboratory screening assay in predicting the field responses of greater yam to Colletotrichum gleosporioides. The scores obtained were tabulated in Table 3.

It is concluded that, by using both laboratory and field disease assessments, 19 accessions were classified as resistant genotypes while the rest 21 were classified as susceptible genotypes.

The released varieties viz. Sree Karthika, Sree Keerthi and Sree Swathy showed resistant scores in the study. Also the susceptible varieties including Sree Neelima and Orissa Elite expressed susceptible scores both under field and lab screening, indicating the effectiveness of the tests done. Identification of resistant yam genotypes viz. Da 110, Jas 2 and TCR 142 will be beneficial for yam breeding to achieve anthracnose resistance and also to identify the resistant genes in future (Fig. 1 and 2). 
Table.1 List of greater yam accessions used for screening against anthracnose

\begin{tabular}{|c|l|l|}
\hline Sl. No. & Genotype & Place of Collection \\
\hline $\mathbf{1 .}$ & Da 110 & Dandakaranya \\
\hline $\mathbf{2 .}$ & Da 198 & Thiruvananthapuram \\
\hline $\mathbf{3 .}$ & Da 200 & NBPGR, Thrissur \\
\hline $\mathbf{4 .}$ & Da 209 & NBPGR, Thrissur \\
\hline $\mathbf{5 .}$ & Da 210 & Coimbatore \\
\hline $\mathbf{6 .}$ & Da 293 & Pathanamthitta \\
\hline $\mathbf{7 .}$ & Da 374 & Pathanamthitta \\
\hline $\mathbf{8 .}$ & Da H $9-196$ & Hybrid, ICAR-CTCRI \\
\hline $\mathbf{9 .}$ & Da H $22-2-3$ & Hybrid, ICAR-CTCRI \\
\hline $\mathbf{1 0 .}$ & Da H 58 FG & Hybrid, ICAR-CTCRI \\
\hline $\mathbf{1 1 .}$ & TCR 308 & NBPGR, Thrissur \\
\hline $\mathbf{1 2 .}$ & TCR 319 & NBPGR, Thrissur \\
\hline $\mathbf{1 3 .}$ & Sree Karthika & Released variety, ICAR-CTCRI \\
\hline $\mathbf{1 4 .}$ & Sree Keerthi & Released variety, ICAR-CTCRI \\
\hline $\mathbf{1 5 .}$ & Sree Swathy & Released variety, ICAR-CTCRI \\
\hline $\mathbf{1 6 .}$ & Da 264 & Thiruvananthapuram \\
\hline $\mathbf{1 7 .}$ & Da 340 & Thiruvananthapuram \\
\hline $\mathbf{1 8 .}$ & Da 817 V & Pathanamthitta \\
\hline $\mathbf{1 9}$. & JAS 2 & Pre-breeding line, ICAR-CTCRI \\
\hline $\mathbf{2 0 .}$ & TCR 226 & NBPGR, Thrissur \\
\hline $\mathbf{2 1 .}$ & TCR 64 & NBPGR, Thrissur \\
\hline $\mathbf{2 2 .}$ & Da 12 & Kottayam \\
\hline $\mathbf{2 3 .}$ & Da 377 & Kollam \\
\hline $\mathbf{2 4 .}$ & Da 489 & Kottayam \\
\hline $\mathbf{2 5 .}$ & TCR 113 & NBPGR, Thrissur \\
\hline $\mathbf{2 6 .}$ & Da 820 & Idukki \\
\hline $\mathbf{2 7 .}$ & Da H $17-5$ & Hybrid, ICAR-CTCRI \\
\hline $\mathbf{2 8 .}$ & Da 810 & Thiruvananthapuram \\
\hline $\mathbf{2 9 .}$ & Orissa Elite & Released variety, ICAR-CTCRI \\
\hline $\mathbf{3 0 .}$ & Sree Neelima & Released variety, ICAR-CTCRI \\
\hline $\mathbf{3 1 .}$ & TCR 208 & NBPGR, Thrissur \\
\hline $\mathbf{3 2 .}$ & TCR 282 & NBPGR, Thrissur \\
\hline $\mathbf{3 3 .}$ & Da 508 & Assam \\
\hline $\mathbf{3 4 .}$ & TCR 102 & NBPGR, Thrissur \\
\hline $\mathbf{3 5 .}$ & TCR 342 & NBPGR, Thrissur \\
\hline $\mathbf{3 6 .}$ & Da 503 & Pre-breeding line, ICAR-CTCRI \\
\hline $\mathbf{3 7 .}$ & Da H $24-6-3$ & Hybrid, ICAR-CTCRI \\
\hline $\mathbf{3 8 .}$ & TCR 142 & NBPGR, Thrissur \\
\hline $\mathbf{3 9 .}$ & Da 509 & Thiruvananthapuram \\
\hline $\mathbf{4 0 .}$ & TCR 43 & NBPGR, Thrissur \\
\hline & & \\
\hline
\end{tabular}


Table.2 Categorisation of resistance against Anthracnose disease in greater Yam

\begin{tabular}{|l|l|}
\hline Score index & Category \\
\hline $\mathbf{0}$ & Immune \\
\hline $\mathbf{1}$ & Highly resistant \\
\hline $\mathbf{2}$ & Resistant \\
\hline $\mathbf{3}$ & Moderately susceptible \\
\hline $\mathbf{4}$ & Susceptible \\
\hline $\mathbf{5}$ & Highly susceptible \\
\hline
\end{tabular}

Table.3 Scores obtained by field and lab screening

\begin{tabular}{|c|c|c|c|c|}
\hline SI. No. & GENOTYPE & FIELD SCORE & LAB SCORE & $R / S$ \\
\hline 1 & Da 110 & 1 & 0 & $\mathrm{R}$ \\
\hline 2 & Da 198 & 2 & 3 & $\mathrm{~S}$ \\
\hline 3 & Da 200 & 2 & 1 & $\mathrm{R}$ \\
\hline 4 & Da 209 & 3 & 1 & $\mathrm{R}$ \\
\hline 5 & Da 210 & 3 & 1 & $\mathrm{R}$ \\
\hline 6 & Da 293 & 1 & 2 & $\mathrm{R}$ \\
\hline 7 & Da 374 & 2 & 2 & $\mathrm{R}$ \\
\hline 8 & DaH 9-196 & 1 & 1 & $\mathrm{R}$ \\
\hline 9 & DaH 22-2-3 & 2 & 2 & $\mathrm{R}$ \\
\hline 10 & DaH 58FG & 1 & 1 & $\mathrm{R}$ \\
\hline 11 & TCR 308 & 2 & 2 & $\mathrm{R}$ \\
\hline 12 & TCR 319 & 2 & 2 & $\mathrm{R}$ \\
\hline 13 & Sree Karthika & 3 & 1 & $\mathrm{R}$ \\
\hline 14 & Sree Keerthi & 1 & 1 & $\mathrm{R}$ \\
\hline 15 & Sree Swathy & 1 & 2 & $\mathrm{R}$ \\
\hline 16 & Da 264 & 2 & 2 & $\mathrm{R}$ \\
\hline 17 & Da 340 & 0 & 3 & $\mathrm{R}$ \\
\hline 18 & Da $817 \mathrm{~V}$ & 1 & 4 & $\mathrm{~S}$ \\
\hline 19 & JAS 2 & 1 & 0 & $\mathrm{R}$ \\
\hline 20 & TCR 226 & 1 & 4 & $\mathrm{~S}$ \\
\hline 21 & TCR 64 & 1 & 3 & $\mathrm{~S}$ \\
\hline 22 & $\mathrm{Da} 12$ & 1 & 4 & $\mathrm{~S}$ \\
\hline 23 & Da 377 & 3 & 2 & $\mathrm{~S}$ \\
\hline 24 & Da 489 & 2 & 2 & $\mathrm{R}$ \\
\hline 25 & TCR 113 & 1 & 1 & $\mathrm{R}$ \\
\hline 26 & Da 820 & 4 & 5 & $\mathrm{~S}$ \\
\hline 27 & Da H 17-5 & 3 & 3 & $\mathrm{~S}$ \\
\hline 28 & Da 810 & 3 & 3 & $\mathrm{~S}$ \\
\hline 29 & Orissa Elite & 4 & 3 & $\mathrm{~S}$ \\
\hline 30 & Sree Neelima & 5 & 4 & $\mathrm{~S}$ \\
\hline 31 & TCR 208 & 3 & 1 & $\mathrm{R}$ \\
\hline 32 & TCR 282 & 3 & 5 & $\mathrm{~S}$ \\
\hline 33 & Da Assam & 2 & 4 & $\mathrm{~S}$ \\
\hline 34 & TCR 102 & 1 & 4 & $\mathrm{~S}$ \\
\hline 35 & TCR 342 & 3 & 5 & $\mathrm{~S}$ \\
\hline 36 & Da 503-O & 2 & 5 & $\mathrm{~S}$ \\
\hline 37 & $\mathrm{DaH} 24-6-3$ & 5 & 5 & $\mathrm{~S}$ \\
\hline 38 & TCR 142 & 0 & 1 & $\mathrm{R}$ \\
\hline 39 & Da 509 & 3 & 5 & $\mathrm{~S}$ \\
\hline 40 & TCR 43 & 3 & 5 & $\mathrm{~S}$ \\
\hline
\end{tabular}


Fig.1 Scoring chart for Yam Anthracnose

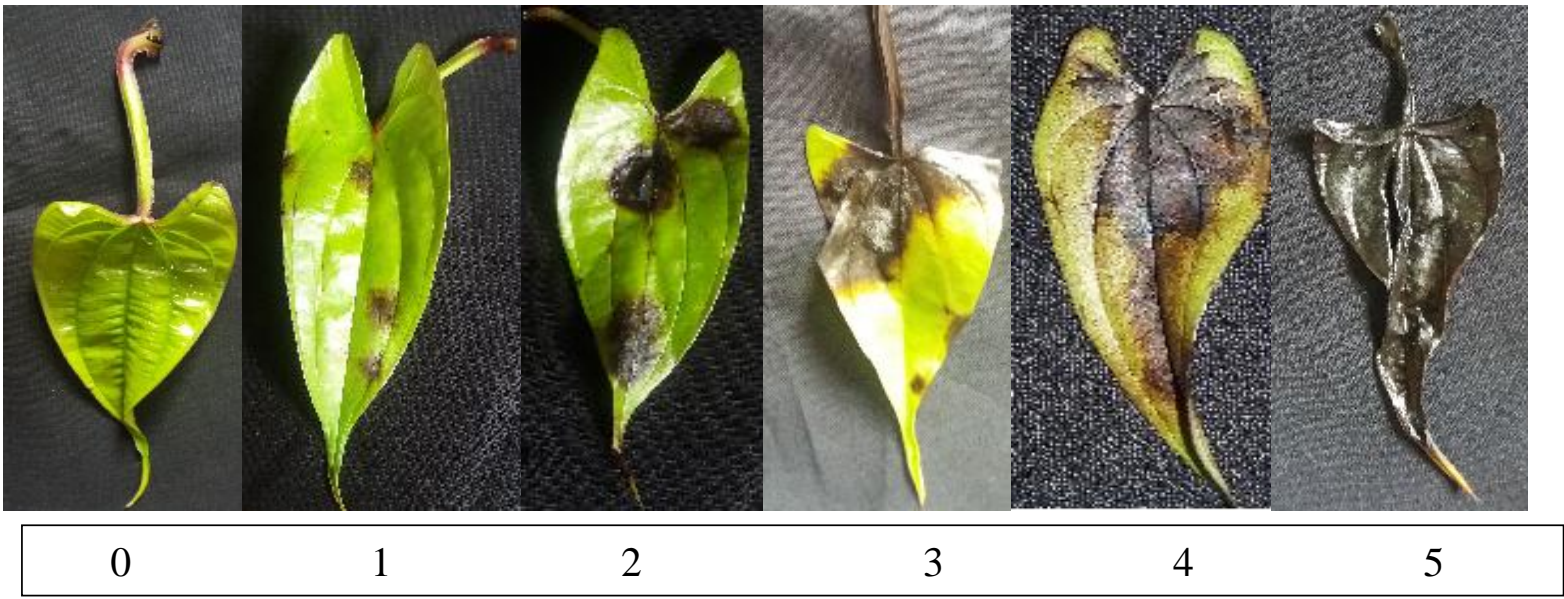

Fig.2 Lab screening of highly resistant Sree Karthika and highly susceptible Sree Neelima

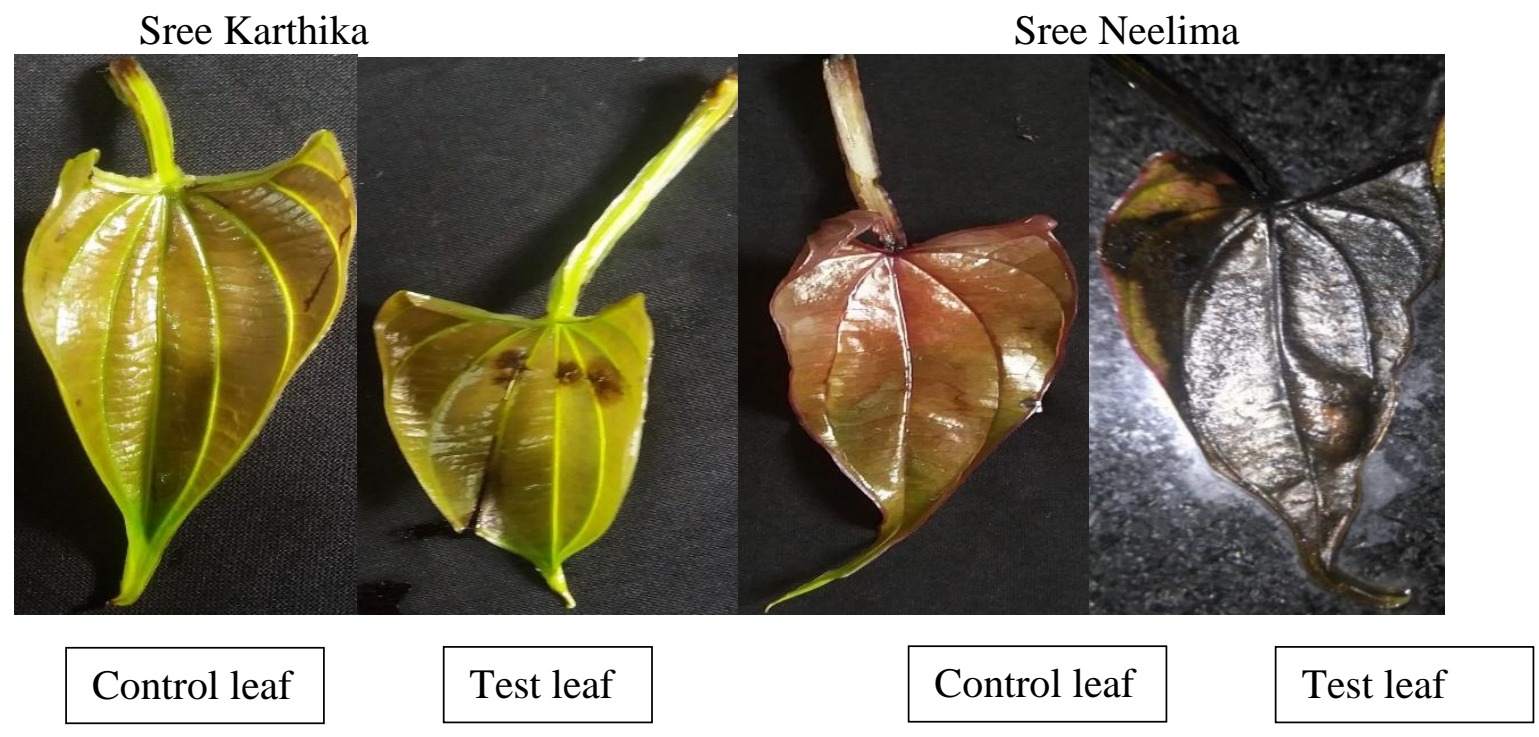

\section{Acknowledgement}

The authors thank College of Agriculture, Vellayani and ICAR-CTCRI for allowing to conduct the research work and the facilities provided.

\section{References}

Amusa, N. A. 1997. Fungi associated with anthracnose symptoms of yam (Dioscorea spp.) in South-west Nigeria and their roles in. Crop Res. 13:177183.

ICAR-CTCRI. 2016. Annual Report 2015-16. ICAR-Central Tuber Crops Research Institute, Thiruvananthapuram. Kerala, India, pp. 54.

Lebot, V. 2009. Tropical root and tuber crops: cassava, sweet potato, yams and aroids. CABI Publishers, Wallingford, 414p.

Muzac Tucker, I., Asemota, H. N. and Ahmad, M. H. 1993. Biochemical 
composition and storage of Jamaican yams (Dioscorea sp). J. Sci. Food Agric. 62(3): 219-224.

Nwankiti, A. O. and Ene, L. S. O. 1984. Advances in the study of anthracnose/blotch disease of Dioscorea alata in Nigeria. In: Shadier, F. S. and Rincon, H. (eds), Int. Soc. Trop. Root Crops. Proceedings of the $6^{\text {th }}$ Symposium Lima, Peru, pp. 633-640.

Onyeka, T.J., Petro, D., Anon, G., Etienne, S. and Rubens, S. 2006. Resistance in water yam (Dioscorea alata) cultivars in the French West Indies to anthracnose disease based on tissue culture derived whole plant assay. Plant pathol. 55(5): 671-678.

Poolsawat, O., Tharapreuksapong, A., Wongkaew, S., Chaowiset, W. and Tantasawat, P. 2012. Laboratory and field evaluations of resistance to
Sphaceloma ampelinum causing anthracnose in grapevine. Australas. Plant Pathol. 41(3): 263-269.

Prasad, N. and Singh, R. D. 1960. Anthracnose disease of Dioscorea alata L. Curr. Sci. 29(2): 66-67.

Singh, R. D., Prasad, N., Mathur, R. L. 1966. On the taxonomy of the fungus causing anthracnose of Dioscorea alata L. Indian Phytopathol. 19:65- 71.

Tay, D. 2013. Tropical and subtropical root and tuber crops. In: Normah, M. N., Chin, H. F., and Reed, B. M. (ends), Conservation of tropical plant species. Springer, New York, pp. 249-292.

Winch, J. E., Newhook, F. J., Jackson, G. V. H., and Cole, J. S. 1984. Studies of Colletotrichum gloeosporioides disease on yam, Dioscorea alata in Solomon Islands. Plant Pathol. 33: 467-477.

\section{How to cite this article:}

Arya, R.S., M.N. Sheela, M.L. Jeeva and Abhilash, P.V. 2019. Identification of Host Plant Resistance to Anthracnose in Greater yam (Dioscorea alata L.). Int.J.Curr.Microbiol.App.Sci. 8(08): 1690-1696. doi: https://doi.org/10.20546/ijcmas.2019.808.199 